\title{
Anastrozole and celecoxib for endometriosis treatment, good to keep them apart?
}

\author{
Carla N Olivares, Mariela A Bilotas, Analía G Ricci, Rosa Inés Barañao and Gabriela F Meresman \\ Instituto de Biología y Medicina Experimental (IBYME), CONICET, C1428ADN, Ciudad Autónoma de Buenos Aires, \\ Vuelta de Obligado 2490, Buenos Aires, Argentina \\ Correspondence should be addressed to C N Olivares; Email: carla.olivares@ibyme.conicet.gov.ar
}

\begin{abstract}
Endometriosis is a benign gynecological disease. Cyclooxygenase-2 (COX-2) and aromatase proteins have been shown to be overexpressed in eutopic endometrium from women suffering from this disease compared to disease-free women. Furthermore, inhibition of these molecules individually was demonstrated to have antiproliferative and proapoptotic effects both in vitro and in vivo in several models. In this study, the effect of combining celecoxib, a selective COX-2 inhibitor, and anastrozole, an aromatase inhibitor, on the implantation and growth of endometriotic like lesions in a murine model of endometriosis was evaluated. Endometriosis was surgically induced in female BALB/c mice. After 28 days of treatment with celecoxib, anastrozole, or their combination, animals were killed and lesions were counted, measured, excised, and fixed. Immunohistochemistry for proliferating cell nuclear antigen and CD34 was performed for assessment of cell proliferation and vascularization. TUNEL technique was performed for apoptosis evaluation. Celecoxib was the only treatment to significantly reduce the number of lesions established per mouse, their size and vascularized area. In addition, cell proliferation was significantly diminished and apoptosis was significantly enhanced by both individual treatments. When the therapies were combined, they reversed their effects. These results confirm that celecoxib and anastrozole separately decrease endometriotic growth, but when combined they might have antagonizing effects.
\end{abstract}

Reproduction (2013) 145 119-126

\section{Introduction}

Endometriosis is a benign disease that is characterized by the presence of endometrial tissue outside the uterine cavity where it proliferates and forms new blood vessels essential for its further development (Lousse et al. 2012). As an estrogen-dependent disease, treatments available up to date aim mainly at reducing estrogen levels (Ozkan et al. 2008). As endometriosis affects women in reproductive age and given that current available treatments mostly impede ovulation (Rocha etal.2012), it is the goal of recent research to find alternatives to the existing treatments reducing the side effects of those now accessible.

We and others have studied the involvement of cyclooxygenase-2 (COX-2) in this pathology (Matsuzaki et al. 2004, Banu et al. 2008, Olivares et al. 2008, 2011), which has been described to be overexpressed not only in eutopic and ectopic endometrium from endometriosis patients (Ota et al. 2001, Fagotti et al. 2004) but also in a wide variety of cancers (Mendes et al. 2009, Ghosh et al. 2010, Wang et al. 2010). Selective COX-2 inhibitors are a special class of nonsteroidal antiinflammatory drugs that were developed to treat pain and inflammation without inhibiting COX-1, thus sparing the gastrointestinal system (Wadman 2007). The COXs are the enzymes responsible for the synthesis of pain mediators including prostaglandins (PGs). Particularly, high concentration of $\mathrm{PGE}_{2}$ has been found in the peritoneal fluid of patients with endometriosis, primarily provided by activated macrophages and the endometriotic lesions (Wu et al. 2010). Our group has demonstrated that selective inhibition of COX-2 activity with celecoxib reduces the proliferation rate of endometrial epithelial cells as well as it augments their apoptosis levels both in vitro and in vivo (Olivares et al. 2008, 2011). Similar results were obtained by other investigators demonstrating that the inhibition of COX-2 activity has antiproliferative, proapoptotic, and antiangiogenic effects in several in vivo and in vitro cancer models (Gupta et al. 2004, Basu et al. 2005, Dandekar et al. 2005, Barnes et al. 2007) and in other models of endometriosis (Dogan et al. 2004, Laschke et al. 2007, Machado et al. 2010). Moreover, a COX-2 inhibitor has been used in a pilot study evaluating pain response in endometriosis patients with good results (Cobellis et al. 2004).

Similarly, aromatase has also been found to be overexpressed in endometriosis with higher protein and mRNA levels in eutopic endometrium from patients compared with control women as well as in ectopic endometrium (Bulun et al. 1997, 2002, Kyama et al. 2008). In this sense, two aromatase inhibitors, letrozole 
and anastrozole, have also been tested in vitro and in vivo in our laboratory and demonstrated to have antiproliferative and proapoptotic effects (Meresman et al. 2005, Bilotas et al. 2010).

COX-2 is overexpressed in some malignancies including carcinoma of the breast. COX2 mRNA and protein levels have been found to correlate with aromatase levels within human breast cancer tissue. The current understanding of the role of COX-2 in breast cancer suggests that COX-2 inhibitors may have a role in chemoprevention, which is based in part on the generic issues of anti-angiogenesis and proapoptotic processes and in part on a tissue-specific inhibition of estrogen synthesis (Davies et al. 2002). It has been reported that celecoxib induces a marked inhibition of aromatase protein expression, assessed by western blot, in human breast cancer cell lines (Bocca et al. 2011). In addition, treatment with COX2 siRNAs resulted in suppression of the aromatase gene CYP19A1 (CYP19) in breast cancer cells (Brueggemeier et al. 2007). In another experimental model, Sirianni et al. (2009) reported that inhibition of COX-2 downregulates aromatase activity and decreases proliferation of Leydig tumor cells. In addition, previous studies had shown that aromatase and COX-2 simultaneous inhibition might have additive or even synergic effects (Bundred \& Barnes 2005, Ebert et al. 2005, Chow et al. 2008, Dirix et al. 2008, Falandry et al. 2009).

Furthermore, a feed forward loop has been described between aromatase and $\mathrm{PGE}_{2}$ in endometriosis. Aromatase synthesizes estrogens, which in turn stimulate the production of $\mathrm{PGE}_{2}$ via COX-2, and $\mathrm{PGE}_{2}$ stimulates aromatase activity (Bulun et al. 2002). This describes a perfect circle in this system in which high expression of aromatase will produce high concentrations of estrogens, which will stimulate COX-2 activity producing high concentrations of $\mathrm{PGE}_{2}$, stimulating again aromatase.

Considering all these data and in sight of the feed forward loop established between these molecules in endometriosis, we decided to investigate the effect of combining a COX-2 inhibitor with an aromatase inhibitor, celecoxib and anastrozole respectively, in a murine model of endometriosis.

For this purpose, we treated mice with induced endometriotic like lesions with anastrozole, celecoxib, or both drugs combined, during a 4-week period and studied their effects on the development of the disease and cell proliferation, apoptosis, and vascularization within the lesions.

\section{Results}

\section{Celecoxib inhibits the establishment and growth of endometriotic like lesions}

After 4 weeks of treatment with anastrozole, celecoxib, or their combination, animals were killed and the abdominal cavity was explored to localize and measure the lesions developed. Figure 1 shows the results obtained for the number of lesions established, according to the treatment the animals received, as well as the volume of those developed.

When mice received celecoxib as the only treatment, not only the lesions established diminished compared to the control group $(P<0.05$; Fig. $1 \mathrm{~A})$ but also the size of those established and developed was significantly smaller $(P<0.01$ vs control; Fig. 1B). However, when animals received either anastrozole alone or combined with celecoxib, the number of lesions established as well as their size did not differ from those of the control group.
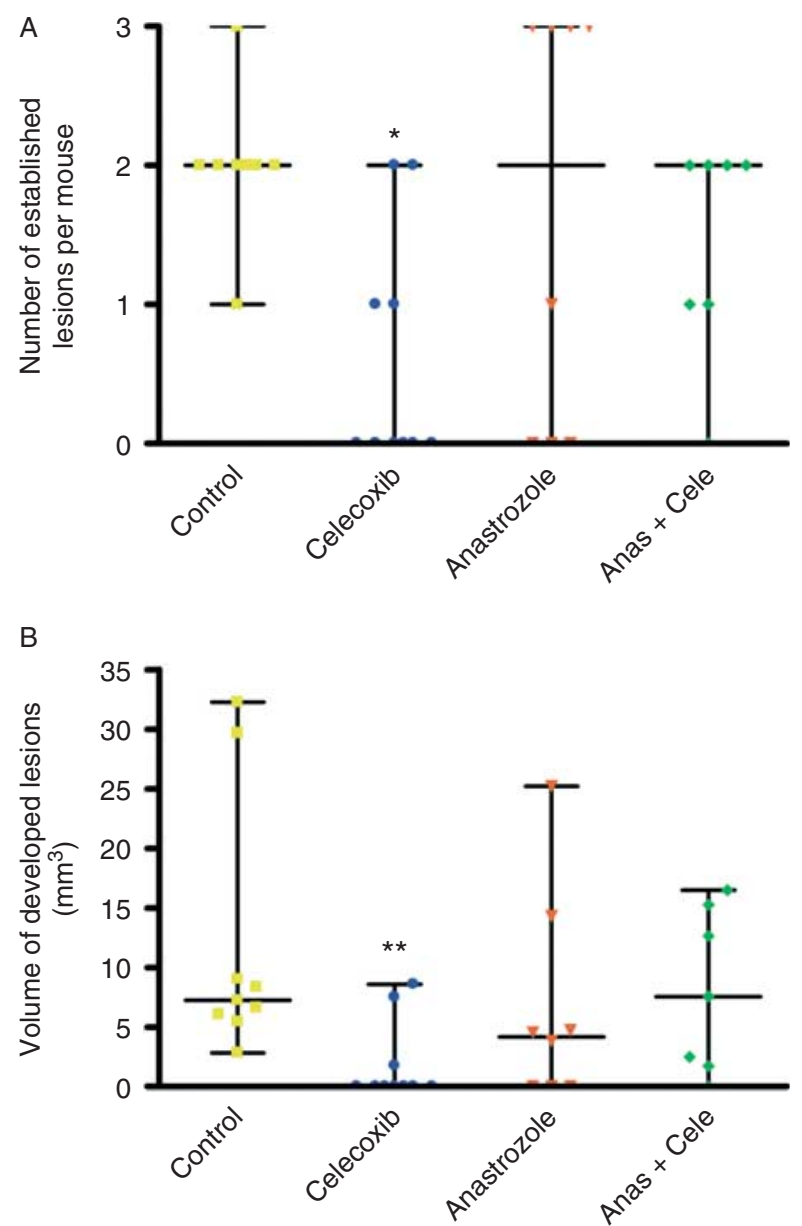

Figure 1 Celecoxib reduces the number and size of established lesions. Mice underwent surgery for endometriosis induction. After 28 days of treatment with vehicle, celecoxib, anastrozole, or both drugs simultaneously, mice were killed and the number of lesions established was counted and measured. (A) Celecoxib significantly reduced the number of lesions established per mouse. Scatter plot for lesion establishment; median, minimum, and maximum are shown. Control, 2 (1-3); celecoxib, 0 (0-2); anastrozole, 2 (0-3); Anas + Cele, 2 (0-2). (B) Celecoxib had a significant effect reducing endometriotic like lesion size. Scatter plot for the development of lesions in each group; median, minimum, and maximum are shown. Control, 7.238 (2.832-32.28); celecoxib, 0 (0-8.588); anastrozole, 4.177 (0-25.21); Anas + Cele, 7.574 (0-16.49). $n=9$ (control), 10 (celecoxib), 8 (anastrozole), and 7 (Anas + Cele). ${ }^{*} P<0.05$ vs control group; ${ }^{* *} P<0.01$ vs control group. 


\section{The COX-2 and aromatase inhibitors affect endometriotic like lesion development}

Developed endometriotic like lesions were excised and fixed for cell proliferation, apoptosis, and vascularization evaluation. Cell proliferation in the epithelial fraction of the lesions was significantly diminished compared with the control group when animals were treated with celecoxib or anastrozole separately $(P<0.05$ for both groups vs control); when the treatments were combined, cell proliferation within the lesions as assessed by proliferating cell nuclear antigen (PCNA) immunohistochemistry was similar to the control group $(P>0.05)$. The results are shown in Fig. 2A.

Accordingly, the number of apoptotic epithelial cells was quantified by the TUNEL technique and the results showed that the combination of the compounds had no effect on cell death whereas the administration of either of them alone significantly enhanced TUNEL-positive cells $(P<0.05$ for anastrozole or celecoxib vs control; $P>0.05$ for anastrozole + celecoxib vs control). Results are shown in Fig. 2B.

When vascular density was assessed within the endometriotic like lesions by immunohistochemistry of CD34, only the treatment of celecoxib administered on its own showed an inhibitory effect $(P<0.05$ vs control). The aromatase inhibitor alone or in combination with the COX-2 inhibitor had no effect on vascular density compared to the control group ( $P>0.05$; Fig. 3 ).

\section{COX-2 immunostaining would be enhanced by celecoxib and inhibited by anastrozole}

COX-2 protein expression was evaluated in a semiquantitative fashion on developed endometriotic like lesions after treatment with celecoxib, anastrozole, or their combination. When animals received celecoxib alone, COX-2 immunoreactivity was apparently stimulated while anastrozole seemed to inhibit it, in both cases, compared to the control group. When the compounds were administered in combination, the immunostaining of COX-2 was comparable to that in the lesions from control mice. However, there was no statistical significance in the changes observed. In all cases, and as reported earlier (Hayes \& Rock 2002), immunoreactivity of COX-2 was evident both in the epithelial and stromal fraction but higher in the epithelial one. Results are shown in Fig. 4.

\section{Discussion}

Endometriosis affects a large number of women all over the world, and great efforts are being taken by researchers to give better and longer lasting answers to patients. Treatment for endometriosis is usually performed with surgery and/or medications. Up-to-date treatment options are poor and do not really cure this disease; they aim mainly at reducing pain and endometriotic growth. Nevertheless, the high recurrence rate of this
A

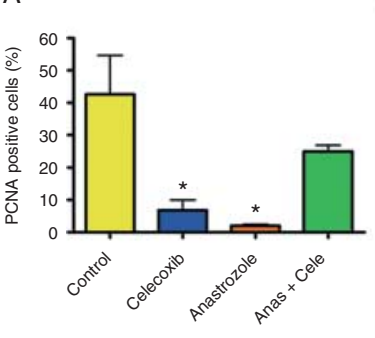

B

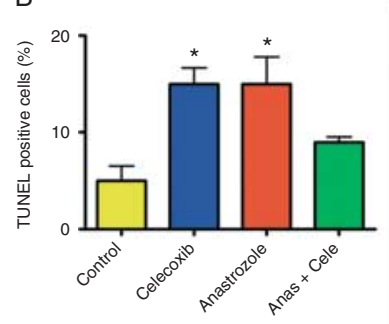

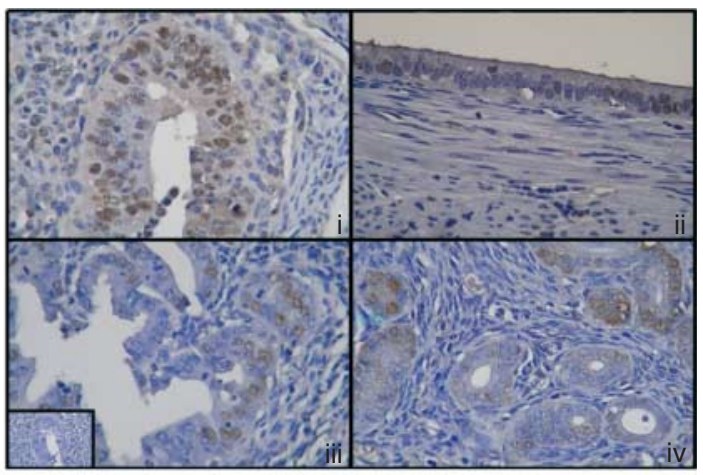

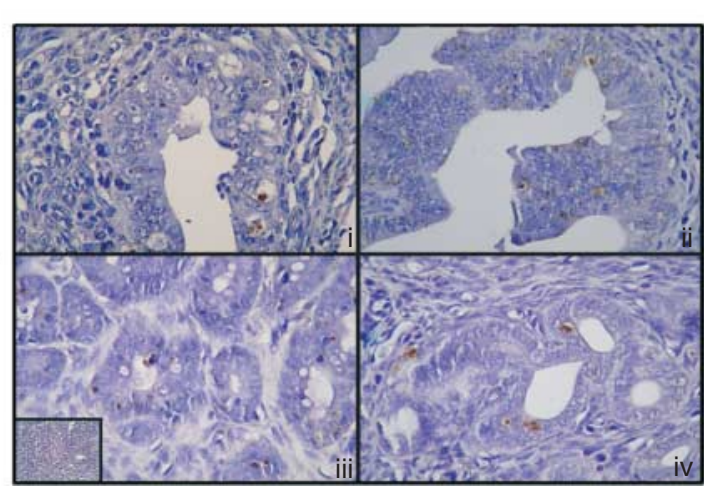

Figure 2 Effect of celecoxib and anastrozole on endometriotic like lesion development. Mice underwent surgery for endometriosis induction. After 28 days of treatment with vehicle, celecoxib, anastrozole, or both drugs simultaneously, mice were killed and implants were removed and fixed. Cell proliferation within the implants was evaluated by immunohistochemistry of PCNA. Apoptosis was evaluated by TUNEL technique. (A) Left panel: after treatment with celecoxib or anastrozole separately, epithelial cell proliferation was significantly diminished compared with control mice. (B) After treatment with celecoxib or anastrozole separately, epithelial cell apoptosis was enhanced compared with control group. Results are expressed as mean \pm S.E.M. ${ }^{*} P<0.05$ vs control group. $n=5$ for all groups. Right panels: representative micrographs of (A) PCNA and (B) TUNEL staining. (i) Control group, (ii) celecoxib group, (iii) anastrozole group, (iv) celecoxib + anastrozole group. Insets: negative controls, an immunoglobulin of the same immunoglobulin class and concentration as the primary antibody was used for PCNA immunohistochemistry and sections were incubated in the absence of TdT enzyme for TUNEL. Magnification, $400 \times$. 


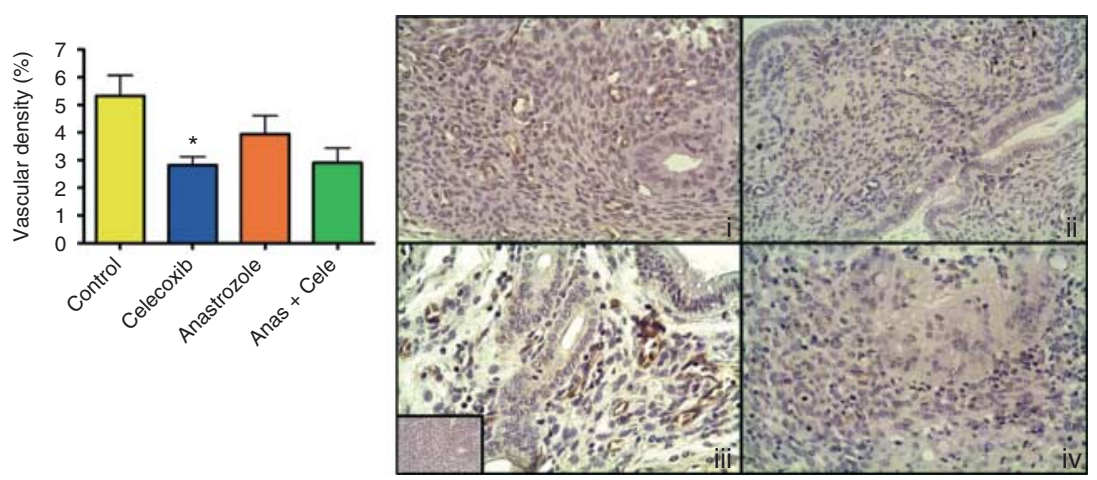

Figure 3 Effect of celecoxib on endometriotic like lesion vascular density. Mice underwent surgery for endometriosis induction. After 28 days of treatment with vehicle, celecoxib, anastrozole, or both drugs simultaneously, mice were killed and implants were removed and fixed. Vascular density within the implants was evaluated performing immunohistochemistry of CD34. Left panel: after treatment with celecoxib, vascular density was diminished compared with control mice. Results are expressed as mean \pm s.E.M. ${ }^{*} P<0.05$ vs control group. $n=5$ for all groups. Right panel: representative micrographs of CD34 staining. (i) Control group, (ii) celecoxib group, (iii) anastrozole group, (iv) celecoxib + anastrozole group. Inset: negative control, an immunoglobulin of the same immunoglobulin class and concentration as the primary antibody was used. Magnification, $400 \times$.

illness is one of the most challenging problems we face nowadays. In this sense, investigations are focusing on finding new and more effective alternatives for patients.

In this study, and taking into account previous results obtained in our laboratory (Bilotas et al. 2010, Olivares et al. 2011) and earlier promising results obtained in cancer (Chow et al. 2008, Falandry et al. 2009), we decided to combine two inhibitors: COX-2 and aromatase. Already some years ago, Ebert et al. (2005) reviewed the importance of aiming at these molecules given the abnormalities present within the eutopic and ectopic endometrium of endometriosis patients and acknowledging the positive feedback loop present between these molecules (Bulun et al. 2002).

Indeed, few studies had been conducted in breast cancer patients combining exemestane, an aromatase inhibitor, with celecoxib with somewhat inconclusive results. While some authors suggested that the addition of celecoxib to exemestane treatment might have promising benefits (Chow et al. 2008, Falandry et al. 2009), others did not find a beneficial effect from this combination (Dirix et al. 2008).

Our first results showed that celecoxib was the only treatment capable of reducing not only the size of established lesions but also the number of lesions established. We had already seen this strong inhibitory effect of celecoxib in a previous work; at that time, we had combined the treatment of celecoxib with a PPAR $\gamma$ agonist, rosiglitazone, obtaining no additional benefit with this combination (Olivares et al. 2011). In this study, the treatment with the aromatase inhibitor and the combination of both inhibitors did not reduce the number of lesions established nor their size compared to the control animals.

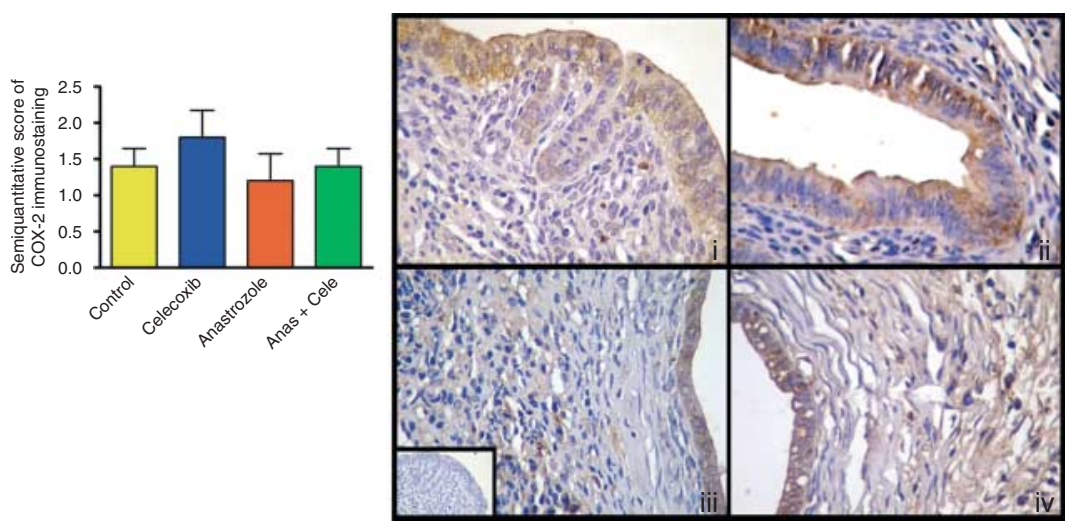

Figure 4 Effect of celecoxib and anastrozole on COX-2 immunoreactivity. Mice underwent surgery for endometriosis induction. After 28 days of treatment with vehicle, celecoxib, anastrozole, or both drugs simultaneously, mice were killed and implants were removed and fixed. COX-2 expression was evaluated performing immunohistochemistry. Left panel: semiquantification of the immunostaining of COX-2 in the developed lesions. When treated with celecoxib, COX-2 immunostaining showed a tendency to be enhanced; with anastrozole, reduced; and when combined, it seemed unaltered; in all cases compared with control mice. Results are expressed as mean \pm s.E.M. $P>0.05$ vs control group. $n=5$ for all groups. Right panel: representative micrographs of COX-2 staining. (i) Control group, (ii) celecoxib group, (iii) anastrozole group, (iv) celecoxib + anastrozole group. Inset: negative control, an immunoglobulin of the same immunoglobulin class and concentration as the primary antibody was used. Magnification, $400 \times$. 
Even though aromatase and COX-2 inhibition had been postulated to have additive or even synergic effects in breast cancer (Goss \& Strasser-Weippl 2004, Chow et al. 2008), some authors have not found a clear beneficial effect from this combination (Dirix et al. 2008, Falandry et al. 2009). The results we are presenting are more in agreement with the latter.

We then investigated the rate of cell proliferation and apoptosis in the lesions developed in all groups. We observed that cell proliferation in the epithelial fraction of the lesions was significantly diminished and apoptotic levels were significantly augmented, when animals were treated with celecoxib or anastrozole separately compared with the control group. It is important to note that even though the rate of cell proliferation was seen significantly reduced in both of these groups, the incidence of this decrease was only evidenced macroscopically, in the celecoxib-treated animals at the doses and period tested. It was also observed that the administration of anastrozole and celecoxib together reversed the effects of either of them alone. Based on these data, we could speculate that these two compounds, against all odds, were having an antagonistic effect, but further studies are needed to test this hypothesis.

On the other hand, we only obtained a significant reduction in vascularization with the treatment with celecoxib alone. In accordance with our results, treatment with another selective COX-2 inhibitor had been reported to reduce microvessel density in a SCID mouse model of endometriosis (Ozawa et al. 2006). Furthermore, another study in a xenograft model of breast cancer showed that the use of letrozole, another aromatase inhibitor, did not reduce the number of CD31-stained vessels, another well-established vascularization marker (Banerjee et al. 2010).

In contrast, Hull et al. found that nimesulide does not reduce lesion size nor blood vessel development in an estrogen-supplemented nude mouse model of endometriosis. The authors suggest that the effect of COX-2 inhibition may be obscured by iatrogenically administered estrogen (Hull et al. 2005). Nevertheless, other authors have demonstrated COX-2 inhibitors to be effective in ovariectomized endometriosis mouse models (Efstathiou et al. 2005, Ozawa et al. 2006).

In this work, we have also examined COX-2 immunoreactivity in the developed endometriotic lesions. Although we did not obtain a statistical significant difference in the changes of COX-2 immunostaining, we observed a tendency to be enhanced when the mice received celecoxib while the aromatase inhibitor reduced it, both compared with the control group. These results are in agreement with the reports that have established the existence of a negative feedback loop between the product from the activity of COX-2 and its protein levels. When the activity of the enzyme is inhibited, this loop disappears and its protein levels augment (Basu et al. 2005, Ohneseit et al. 2007). On the other hand, it is known that the product from aromatase activity stimulates mRNA and protein levels, as well as the activity, of COX-2 (Bulun et al. 2002). With the support from previous reports, the observed reduction in COX-2 immunostaining after anastrozole treatment is consistent with the interaction between these two enzymes and their products. Furthermore, even though it has been reported that the inhibition of COX-2 activity also inhibits the protein expression of aromatase in breast cancer cell lines in vitro (Bocca et al. 2011), when exemestane was combined with celecoxib, the protein levels of aromatase were seen unaltered in breast cancer patients (Lustberg et al. 2011).

There are no studies published in the field of endometriosis where the combination of anastrozole with celecoxib, or any other aromatase or COX-2 inhibitors, has been tested. In breast cancer research, the combination of celecoxib has been evaluated with exemestane. Exemestane and anastrozole, both well-known and thoroughly studied third-generation aromatase inhibitors, do have distinct ways of action. Anastrozole, as well as letrozole, is a reversible nonsteroidal inhibitor, whereas exemestane is an irreversible steroidal inhibitor (Geisler 2011). Maybe it is on this difference where it resides the contrasting results we have obtained.

Furthermore, we have performed this study using the mentioned mouse model of endometriosis and it has to be considered the possibility that women's endometrium might not have the same response to the treatment with these compounds. The tissue implanted in the mouse peritoneum in this particular model consists of not only endometrial cells but it also contains myometrial tissue; this is not the case in the endometriotic lesions developed in women. Moreover, women's endometriotic lesions are exposed to the natural hormonal fluctuations due to the menstrual cycle rather than the much shorter and more rapidly changing estrous cycle of the mouse, which may further affect the tissue developing in the peritoneal cavity. Further studies should be held in humans as to being able to state the certainty of the results presented here. This is an approach and a modelization of a very complicated human disease and the results should be interpreted in this sense. Nevertheless, this is a well-established and accepted model of endometriosis, which has been thoroughly used not only in our laboratory (Bilotas et al. 2010, Olivares et al. 2011, Ricci et al. 2011) but by other investigators too (Fang et al. 2002, Becker et al. 2006, Grummer 2006, Pelch et al. 2010).

To the best of our knowledge, this is the first study to investigate the combination of these two compounds in endometriosis research. More studies should be addressed to study the pharmacology of these compounds as to evaluate whether they might be having antagonizing effects. In the light of the results presented, 
it may be a possibility. Our previous and present works have undoubtedly demonstrated the efficacy of celecoxib and anastrozole as monotherapies, and although their combination should benefit the patient theoretically, we cannot state it so far.

\section{Materials and Methods}

\section{Animals}

In this study, 40 2-month-old female BALB/c mice were used. All procedures were performed according to NIH Guidelines for the Care and Use of Laboratory Animals and approved by the Ethics and Research Committee from the Instituto de Biología y Medicina Experimental (Buenos Aires, Argentina). A total of six animals died or were killed 2 to 3 days after surgery because they did not fully recover from the procedure.

\section{Surgical induction of endometriosis and treatment}

Endometriosis-like lesions were induced through transplantation of one of the uterine horns to the bowel mesentery as described previously (Bilotas et al. 2010, Olivares et al. 2011, Ricci et al. 2011). Briefly, animals were deeply anesthetized with an i.p. injection of ketamine $(100 \mathrm{mg} / \mathrm{kg}$; Holliday Scott, Buenos Aires, Argentina) and xylazine $(10 \mathrm{mg} / \mathrm{kg}$; Richmond, Buenos Aires, Argentina). Mice underwent laparotomy by midventral incision to expose the uterus and intestine. The right uterine horn was removed, opened longitudinally, and cut into square pieces measuring $\sim 4 \mathrm{~mm}^{2}$. Three equal pieces of tissue were then sutured onto serosal layer with a single 6-0 nylon suture (Supralon, Ethicon, NJ, USA) with endometrial tissue facing the serosa. The abdomen was then closed with a 5-0 nylon suture.

Animals were assigned into four different treatment groups: control, $150 \mu \mathrm{l}$ vehicle; celecoxib, $1500 \mathrm{ppm}$ celecoxib (Pfizer) in chow $(+150 \mu \mathrm{l}$ vehicle); anastrozole $(0.5 \mathrm{mg} / \mathrm{kg}$ s.c. injection, anastrozole was reconstituted in physiological solution) (AztraZeneca, London, UK), and celecoxib + anastrozole, received the treatments combined. All treatments were administered daily, started in postoperative day 1 and continued during 28 days. The amount of celecoxib consumed by each animal was estimated weighing the chow 1 day and the next, this difference was divided by the number of animals per cage; the chow was replaced and weighed every day. Each animal consumed $4.65 \pm 0.17 \mathrm{mg}$ celecoxib per day. No evidence of toxicity was noted at the doses administered based on body weight, food consumption, grooming behavior, or activity levels compared with controls.

\section{Endometriotic like lesions evaluation}

After 4 weeks of treatment, animals were killed by cervical dislocation. The abdomen was opened by ventral midline incision. Implantation sites were localized by the presence of a lesion or by suture alone. Lesions were counted and measured for volume determination using the formula: $V=(4 / 3) \pi r^{2} R$ (where $r$ and $R$ are the radiuses, $r<R$; Brodie et al. 2003). Then lesions were excised, fixed, and paraffin embedded.
Specimens were cut into $5 \mu \mathrm{m}$ serial sections. Four to five non-contiguous sections from each specimen were stained with hematoxylin-eosin and examined microscopically for the presence of histological hallmarks (glands and stroma) of endometriosis.

\section{Immunohistochemistry for PCNA, CD34, and COX-2}

Serial sections of endometriotic lesions were subjected to standard immunohistochemistry. Tissue sections were incubated overnight with the primary antibody (rabbit anti-mouse PCNA polyclonal, 1:300, FL-261, Santa Cruz Biotechnology; rat anti-mouse CD34 monoclonal, 1:50, ab8158 Abcam, Cambridge, MA, USA; or rabbit anti-COX-2 polyclonal, 1:200, sc-1747, Santa Cruz Biotechnology) at $4{ }^{\circ} \mathrm{C}$. After that, sections were treated for $60 \mathrm{~min}$ with the corresponding secondary biotinylated antibody (goat anti-rabbit IgG, 1:200, B7389; or goat anti-rat IgG 1:500, B7139; both from SigmaAldrich) followed by incubation with streptavidin-peroxidase (LSAB + System, Dako, Carpinteria, CA, USA). Binding was visualized incubating sections with $\mathrm{DAB}$ and lightly counterstaining with haematoxylin, before permanent mounting.

The number of cells expressing immunoreactivity for PCNA was established using a standard light microscope. A total of 300 epithelial cells were counted and the percentage of PCNA-positive cells was calculated. Any nuclear staining was regarded as positive.

For determining the percentage of vascularized area, lesions were analyzed with Image $1.33 \mathrm{u}$ Software $(\mathrm{NIH}$, Bethesda, MD, USA). The area positive for CD34 was visualized and marked or delimited by the usage of this software. For each animal evaluated, ten fields were micrographed; for each micrograph, all positive area/s were delimited, added, and then divided by the total area of the micrograph, obtaining a percentage of vascularized area per micrograph. This process was done for every set of ten micrographs per animal. Then the media for the ten micrographs was calculated, obtaining the media percentage of vascularized area per animal and the media per treatment was calculated (Olivares et al. 2011, Ricci et al. 2011).

A semiquantitative analysis of cells expressing COX-2 immunoreactivity was done using a standard light microscope. Briefly, slides were evaluated blinded to treatment by two independent observers. Ten fields were evaluated, and overall staining was recorded $(0$, absence of staining; 1 , mild staining; 2, moderate staining; and 3, marked).

\section{TUNEL assay}

For apoptosis quantification, sections were processed for in situ immunohistochemical localization of nuclei exhibiting DNA fragmentation using the apoptosis detection kit Apoptag Plus (Chemicon International, Temecula, CA, USA). Sections were treated according to the manufacturer's instructions as described previously (Meresman et al. 2000). The number of cells positive for TUNEL stain was established using a standard light microscope at $400 \times$ magnification. A total of 300 epithelial cells were counted and the percentage of TUNEL-positive cells was calculated. 


\section{Statistical analysis}

Statistical analyses were performed using GraphPad Instat V4.0 Software (for Windows, GraphPad Software, San Diego, CA, USA). Statistical comparisons between groups were performed using nonparametric Kruskal-Wallis test with Dunn's multiple comparison post test. Results were expressed as median (minimum-maximum) or as mean \pm S.E.M. In all cases, statistical significance was considered when $P<0.05$.

\section{Declaration of interest}

The authors declare that there is no conflict of interest that could be perceived as prejudicing the impartiality of the research reported.

\section{Funding}

This study was supported by ANPCYT (Préstamo BID PICT 01632), CONICET (PIP 1223), and Fundación Roemmers, Buenos Aires, Argentina.

\section{References}

Banerjee S, A'Hern R, Detre S, Littlewood-Evans AJ, Evans DB, Dowsett M \& Martin LA 2010 Biological evidence for dual antiangiogenicantiaromatase activity of the VEGFR inhibitor PTK787/ZK222584 in vivo. Clinical Cancer Research 16 4178-4187. (doi:10.1158/10780432.CCR-10-0456)

Banu SK, Lee J, Speights VO Jr, Starzinski-Powitz A \& Arosh JA 2008 Cyclooxygenase-2 regulates survival, migration, and invasion of human endometriotic cells through multiple mechanisms. Endocrinology 149 1180-1189. (doi:10.1210/en.2007-1168)

Barnes NL, Warnberg F, Farnie G, White D, Jiang W, Anderson E \& Bundred NJ 2007 Cyclooxygenase-2 inhibition: effects on tumour growth, cell cycling and lymphangiogenesis in a xenograft model of breast cancer. British Journal of Cancer 96 575-582. (doi:10.1038/sj.bjc. 6603593)

Basu GD, Pathangey LB, Tinder TL, Gendler SJ \& Mukherjee P 2005 Mechanisms underlying the growth inhibitory effects of the cyclooxygenase-2 inhibitor celecoxib in human breast cancer cells. Breast Cancer Research 7 R422-R435. (doi:10.1186/bcr1019)

Becker CM, Sampson DA, Short SM, Javaherian K, Folkman J \& D'Amato RJ 2006 Short synthetic endostatin peptides inhibit endothelial migration in vitro and endometriosis in a mouse model. Fertility and Sterility 85 71-77. (doi:10.1016/j.fertnstert.2005.07.1290)

Bilotas M, Meresman G, Stella I, Sueldo C \& Baranao RI 2010 Effect of aromatase inhibitors on ectopic endometrial growth and peritoneal environment in a mouse model of endometriosis. Fertility and Sterility 93 2513-2518. (doi:10.1016/j.fertnstert.2009.08.058)

Bocca C, Bozzo F, Bassignana A \& Miglietta A 2011 Antiproliferative effects of COX-2 inhibitor celecoxib on human breast cancer cell lines. Molecular and Cellular Biochemistry 350 59-70. (doi:10.1007/s11010010-0682-4)

Brodie A, Jelovac D \& Long BJ 2003 Predictions from a preclinical model: studies of aromatase inhibitors and antiestrogens. Clinical Cancer Research 9 455S-459S.

Brueggemeier RW, Su B, Sugimoto Y, Diaz-Cruz ES \& Davis DD 2007 Aromatase COX in breast cancer: enzyme inhibitors and beyond. Journal of Steroid Biochemistry and Molecular Biology 106 16-23. (doi:10.1016/j.jsbmb.2007.05.021)

Bulun SE, Noble LS, Takayama K, Michael MD, Agarwal V, Fisher C, Zhao Y, Hinshelwood MM, Ito Y \& Simpson ER 1997 Endocrine disorders associated with inappropriately high aromatase expression. Journal of Steroid Biochemistry and Molecular Biology 61 133-139. (doi:10.1016/ S0960-0760(97)80004-0)
Bulun SE, Yang S, Fang Z, Gurates B, Tamura M \& Sebastian S 2002 Estrogen production and metabolism in endometriosis. Annals of the New York Academy of Sciences 955 75-85. (doi:10.1111/j.1749-6632.2002. tb02767.x)

Bundred NI \& Barnes NL 2005 Potential use of COX-2-aromatase inhibitor combinations in breast cancer. British Journal of Cancer 93 (Suppl 1) S10-S15. (doi:10.1038/sj.bjc.6602690)

Chow LW, Yip AY, Loo WT, Lam CK \& Toi M 2008 Celecoxib anti-aromatase neoadjuvant (CAAN) trial for locally advanced breast cancer. Journal of Steroid Biochemistry and Molecular Biology 111 13-17. (doi:10.1016/ j.jsbmb.2008.04.004)

Cobellis L, Razzi S, De Simone S, Sartini A, Fava A, Danero S, Gioffre W, Mazzini M \& Petraglia F 2004 The treatment with a COX-2 specific inhibitor is effective in the management of pain related to endometriosis. European Journal of Obstetrics, Gynecology, and Reproductive Biology 116 100-102. (doi:10.1016/j.ejogrb.2004.02.007)

Dandekar DS, Lopez M, Carey RI \& Lokeshwar BL 2005 Cyclooxygenase-2 inhibitor celecoxib augments chemotherapeutic drug-induced apoptosis by enhancing activation of caspase- 3 and -9 in prostate cancer cells. International Journal of Cancer 115 484-492. (doi:10.1002/ijc. 20878)

Davies G, Martin LA, Sacks N \& Dowsett M 2002 Cyclooxygenase-2 (COX-2), aromatase and breast cancer: a possible role for COX-2 inhibitors in breast cancer chemoprevention. Annals of Oncology 13 669-678. (doi:10.1093/annonc/mdf125)

Dirix LY, Ignacio J, Nag S, Bapsy P, Gomez H, Raghunadharao D, Paridaens R, Jones S, Falcon S, Carpentieri M et al. 2008 Treatment of advanced hormone-sensitive breast cancer in postmenopausal women with exemestane alone or in combination with celecoxib. Journal of Clinical Oncology 26 1253-1259. (doi:10.1200/JCO.2007.13.3744)

Dogan E, Saygili U, Posaci C, Tuna B, Caliskan S, Altunyurt S \& Saatli B 2004 Regression of endometrial explants in rats treated with the cyclooxygenase-2 inhibitor rofecoxib. Fertility and Sterility 82 (Suppl 3) 1115-1120. (doi:10.1016/j.fertnstert.2004.06.033)

Ebert AD, Bartley J \& David M 2005 Aromatase inhibitors and cyclooxygenase-2 (COX-2) inhibitors in endometriosis: new questions - old answers? European Journal of Obstetrics, Gynecology, and Reproductive Biology 122 144-150. (doi:10.1016/j.ejogrb.2005.04.017)

Efstathiou JA, Sampson DA, Levine Z, Rohan RM, Zurakowski D, Folkman J, D'Amato RJ \& Rupnick MA 2005 Nonsteroidal antiinflammatory drugs differentially suppress endometriosis in a murine model. Fertility and Sterility 83 171-181. (doi:10.1016/j.fertnstert.2004. 06.058)

Fagotti A, Ferrandina G, Fanfani F, Legge F, Lauriola L, Gessi M, Castelli P, Barbieri F, Minelli L \& Scambia G 2004 Analysis of cyclooxygenase-2 (COX-2) expression in different sites of endometriosis and correlation with clinico-pathological parameters. Human Reproduction 19 393-397. (doi:10.1093/humrep/deh054)

Falandry C, Canney PA, Freyer G \& Dirix LY 2009 Role of combination therapy with aromatase and cyclooxygenase- 2 inhibitors in patients with metastatic breast cancer. Annals of Oncology 20 615-620. (doi:10.1093/ annonc/mdn693)

Fang Z, Yang S, Gurates B, Tamura M, Simpson E, Evans D \& Bulun SE 2002 Genetic or enzymatic disruption of aromatase inhibits the growth of ectopic uterine tissue. Journal of Clinical Endocrinology and Metabolism 87 3460-3466. (doi:10.1210/jc.87.7.3460)

Geisler J 2011 Differences between the non-steroidal aromatase inhibitors anastrozole and letrozole - of clinical importance? British Journal of Cancer 104 1059-1066. (doi:10.1038/bjc.2011.58)

Ghosh N, Chaki R, Mandal V \& Mandal SC 2010 COX-2 as a target for cancer chemotherapy. Pharmacological Reports 62 233-244.

Goss PE \& Strasser-Weippl K 2004 Prevention strategies with aromatase inhibitors. Clinical Cancer Research 10 372S-379S. (doi:10.1158/10780432.CCR-031210)

Grummer R 2006 Animal models in endometriosis research. Human Reproduction Update 12 641-649. (doi:10.1093/humupd/dml026)

Gupta S, Adhami VM, Subbarayan M, MacLennan GT, Lewin JS, Hafeli UO, Fu P \& Mukhtar H 2004 Suppression of prostate carcinogenesis by dietary supplementation of celecoxib in transgenic adenocarcinoma of the mouse prostate model. Cancer Research 64 3334-3343. (doi:10.1158/0008-5472.CAN-03-2422) 
Hayes EC \& Rock JA 2002 COX-2 inhibitors and their role in gynecology. Obstetrical \& Gynecological Survey 57 768-780. (doi:10.1097) 00006254-200211000-00023)

Hull ML, Prentice A, Wang DY, Butt RP, Phillips SC, Smith SK \& CharnockJones DS 2005 Nimesulide, a COX-2 inhibitor, does not reduce lesion size or number in a nude mouse model of endometriosis. Human Reproduction 20 350-358. (doi:10.1093/humrep/deh611)

Kyama CM, Overbergh L, Mihalyi A, Meuleman C, Mwenda JM, Mathieu C \& D'Hooghe TM 2008 Endometrial and peritoneal expression of aromatase, cytokines, and adhesion factors in women with endometriosis. Fertility and Sterility 89 301-310. (doi:10.1016/j.fertnstert.2007. 02.057)

Laschke MW, Elitzsch A, Scheuer C, Vollmar B \& Menger MD 2007 Selective cyclo-oxygenase-2 inhibition induces regression of autologous endometrial grafts by down-regulation of vascular endothelial growth factor-mediated angiogenesis and stimulation of caspase-3-dependent apoptosis. Fertility and Sterility 87 163-171. (doi:10.1016/j.fertnstert. 2006.05.068)

Lousse JC, Van Langendonckt A, Defrere S, Ramos RG, Colette S \& Donnez J 2012 Peritoneal endometriosis is an inflammatory disease. Frontiers in Bioscience 4 23-40. (doi:10.2741/358)

Lustberg MB, Povoski SP, Zhao W, Ziegler RM, Sugimoto Y, Ruppert AS, Lehman AM, Shiels DR, Mrozek E, Ramaswamy B et al. 2011 Phase II trial of neoadjuvant exemestane in combination with celecoxib in postmenopausal women who have breast cancer. Clinical Breast Cancer 11 221-227. (doi:10.1016/j.clbc.2011.03.022)

Machado DE, Berardo PT, Landgraf RG, Fernandes PD, Palmero C, Alves LM, Abrao MS \& Nasciutti LE 2010 A selective cyclooxygenase-2 inhibitor suppresses the growth of endometriosis with an antiangiogenic effect in a rat model. Fertility and Sterility 93 2674-2679. (doi:10.1016/ j.fertnstert.2009.11.037)

Matsuzaki S, Canis M, Pouly JL, Wattiez A, Okamura K \& Mage G 2004 Cyclooxygenase-2 expression in deep endometriosis and matched eutopic endometrium. Fertility and Sterility 82 1309-1315. (doi:10. 1016/j.fertnstert.2004.03.059)

Mendes RA, Carvalho JF \& Waal I 2009 An overview on the expression of cyclooxygenase- 2 in tumors of the head and neck. Oral Oncology 45 e124-e128. (doi:10.1016/j.oraloncology.2009.03.016)

Meresman GF, Vighi S, Buquet RA, Contreras-Ortiz O, Tesone M \& Rumi LS 2000 Apoptosis and expression of $\mathrm{Bcl}-2$ and Bax in eutopic endometrium from women with endometriosis. Fertility and Sterility 74 760-766. (doi:10.1016/S0015-0282(00)01522-3)

Meresman GF, Bilotas M, Abello V, Buquet R, Tesone M \& Sueldo C 2005 Effects of aromatase inhibitors on proliferation and apoptosis in eutopic endometrial cell cultures from patients with endometriosis. Fertility and Sterility 84 459-463. (doi:10.1016/j.fertnstert.2005.01.137)

Ohneseit PA, Krebiehl G, Dittmann K, Kehlbach R \& Rodemann HP 2007 Inhibition of cyclooxygenase-2 activity by celecoxib does not lead to radiosensitization of human prostate cancer cells in vitro. Radiotherapy and Oncology 82 229-238. (doi:10.1016/j.radonc.2006.11.018)
Olivares C, Bilotas M, Buquet R, Borghi M, Sueldo C, Tesone M \& Meresman G 2008 Effects of a selective cyclooxygenase-2 inhibitor on endometrial epithelial cells from patients with endometriosis. Human Reproduction 23 2701-2708. (doi:10.1093/humrep/den315)

Olivares C, Ricci A, Bilotas M, Baranao RI \& Meresman G 2011 The inhibitory effect of celecoxib and rosiglitazone on experimental endometriosis. Fertility and Sterility 96 428-433. (doi:10.1016/ j.fertnstert.2011.05.063)

Ota H, Igarashi S, Sasaki M \& Tanaka T 2001 Distribution of cyclooxygenase- 2 in eutopic and ectopic endometrium in endometriosis and adenomyosis. Human Reproduction 16 561-566. (doi:10.1093/ humrep/16.3.561)

Ozawa Y, Murakami T, Tamura M, Terada Y, Yaegashi N \& Okamura K 2006 A selective cyclooxygenase-2 inhibitor suppresses the growth of endometriosis xenografts via antiangiogenic activity in severe combined immunodeficiency mice. Fertility and Sterility 86 (Suppl 4) 1146-1151. (doi:10.1016/j.fertnstert.2006.01.057)

Ozkan S, Murk W \& Arici A 2008 Endometriosis and infertility: epidemiology and evidence-based treatments. Annals of the New York Academy of Sciences 1127 92-100. (doi:10.1196/annals.1434.007)

Pelch KE, Schroder AL, Kimball PA, Sharpe-Timms KL, Davis JW \& Nagel SC 2010 Aberrant gene expression profile in a mouse model of endometriosis mirrors that observed in women. Fertility and Sterility 93 1615-1627. (doi:10.1016/j.fertnstert.2009.03.086)

Ricci AG, Olivares CN, Bilotas MA, Meresman GF \& Baranao RI 2011 Effect of vascular endothelial growth factor inhibition on endometrial implant development in a murine model of endometriosis. Reproductive Sciences 18 614-622. (doi:10.1177/1933719110395406)

Rocha AL, Reis FM \& Petraglia F 2012 New trends for the medical treatment of endometriosis. Expert Opinion on Investigational Drugs 21 905-919. (doi:10.1517/13543784.2012.683783)

Sirianni R, Chimento A, De Luca A, Zolea F, Carpino A, Rago V, Maggiolini M, Ando S \& Pezzi V 2009 Inhibition of cyclooxygenase-2 down-regulates aromatase activity and decreases proliferation of Leydig tumor cells. Journal of Biological Chemistry 284 28905-28916. (doi:10.1074/jbc.M109.041020)

Wadman M 2007 The pain game. Nature 448 400-401. (doi:10.1038/ 448400a)

Wang XQ, Yu J, Luo XZ, Shi YL, Wang Y, Wang L \& Li DJ 2010 The high level of RANTES in the ectopic milieu recruits macrophages and induces their tolerance in progression of endometriosis. Journal of Molecular Endocrinology 45 291-299. (doi:10.1677/JME-09-0177)

Wu MH, Lu CW, Chuang PC \& Tsai SJ 2010 Prostaglandin $E_{2}$ : the master of endometriosis? Experimental Biology and Medicine 235 668-677. (doi:10.1258/ebm.2010.009321)

Received 1 October 2012

First decision 29 October 2012

Accepted 12 November 2012 